\title{
Comparison of the Effects of Pilates and Aerobic Exercise on Pain, Menstruation Symptoms, and Balance in Women with Dysmenorrhea
}

\author{
Su-Wan Lee', Won-Seob Shin ${ }^{2}$ \\ 'Department of Physical Therapy, Graduate School of Health and Medicine, Daejeon University, Daejeon, Republic of Korea; ${ }^{2}$ Department of Physical \\ Therapy, College of Health and Medical Science, Daejeon University, Daejeon, Republic of Korea
}

Purpose: Menstruation is associated with menstrual symptoms like pain and balance problems which have an impact on the quality of life. Pilates increases pelvic stability and reduces menstrual pain by inducing abdominal muscle contraction. This study was done to evaluate the effects of Pilates on menstrual pain, symptoms, balance, and quality of life when compared to aerobic exercise.

Methods: Thirty-nine women with menstrual pain were randomly divided into the Pilates group $(n=13)$, aerobics group ( $n=13)$, and control group $(n=13)$. The Pilates group performed lumbar-pelvic stabilization exercises, while the aerobic group ran on a treadmill. The control group did not undergo any intervention. The experimental groups exercised for four weeks (12 sessions) and did not exercise during menstruation. The Y-balance test was performed on the second day of menstruation to evaluate dynamic balance. The questionnaires administered immediately after menstruation were the visual analog scale (VAS), Korea Oswestry Disability Index (ODI), and the modified Menstrual Distress Questionnaire (MDQ). The paired t-test was used to compare the effect of exercise within the three groups and a oneway analysis of variance was used to compare between groups.

Results: VAS and MEDI-Q scores significantly decreased in the Pilates group after 4 weeks compared with those in the aerobic and control groups. Moreover, ODI and Y-balance scores increased in the Pilates group compared with those in the aerobic and control groups $(p<0.05)$.

Conclusion: The Pilates stabilization exercises are effective and help in improving menstrual pain, balance and other menstrual symptoms assessed through ODI, and MEDI-0, compared to aerobic exercises.

Keywords: Pilates exercise, Dysmenorrhea, Menstruation

서 론

월경은 매달 주기적으로 가임기 여성의 자궁내막이 탈락하는 현상 을 말한다. 월경 전, 후 여성은 신체적 변화 및 통증이 동반하면서 사 회 활동 등에 영향을 미친다. 월경 기간 동안 여성 대부분은 통증을 겪는데 이는 부인과 질환에서 가장 흔한 증상 중 하나이다. 20 대 초 반 여성은 다른 연령층보다 전반적으로 월경증상 호소가 더 심하다 고 알려져 있는데, ${ }^{3}$ 통증으로 인해 월경 동안 일상생활에 심각한 지 장을 겪고 있음에도 불구하고 치료를 위한 적극적인 태도가 부족하 며 의료기관 이용률이 매우 저조하다. 월경 통증의 정확한 원인이나 병태 생리학적인 기전은 아직 알려지지 않지만, 이에 관한 많은 연구 가 이루어지고 있으며 현재는 프로스타글란딘의 과다 생성으로 인

Received Sep 15, 2021 Revised Oct 24, 2021

Accepted Oct 25, 2021

Corresponding author Won-Seob Shin

E-mail shinws@dju.kr
한 자궁 근육 수축의 증가로 월경 통증이 발생한다는 이론이 가장 널 리 알려져 있다. ${ }^{5}$

월경을 하는 여성은 골반 안정성이 떨어지면서6 허리골반의 불균 형을 유발할 수 있으며 그로 인하여 잘못된 고유수용감각이 중추신 경계에 입력되어 균형조절이 떨어질 수 있다. 또한 에스트로겐의 영 향으로 발목인대도 느슨함이 증가하면서 발목조절능력이 떨어지며 균형을 쉽게 잃을수 있다.

월경 통증을 치료하기 위해 비스테로이드 염증제 또는 경구용 피 임약이 널리 사용되고 있으나 두통, 위장장애 등의 부작용이 있고, 일 시적인 통증 감소에만 중점을 두고 있어 근본적인 문제 해결은 되지 않는 실정이다.9 비약물적인 월경 통증 치료 중 운동 치료의 필요성이 대두되면서 규칙적인 운동을 하는 집단은 월경 통증 발생률이 현저 
하게 낮으며 월경 시 적당한 강도의 운동은 긍정적인 영향을 준다고 하였다. ${ }^{10}$ 지속적인 유산소 운동을 한 여성은 월경 통증이 줄어들었 으며, ${ }^{11}$ 일상생활 기능과 삶의 질이 향상되었다고 하였고, ${ }^{12}$ 월경 통증 감소를 위한 운동치료에 관한 연구가 끊임없이 이어지고 있다. 운동 치료 중 필라테스는 근골격계 질병과 통증 개선에 효과적이라는 것 이 입증되면서 임상에서 널리 사용되고 있다.13 필라테스는 피드백을 통해 무너진 근 활성 패턴을 정상인과 비슷하게 근 활성 패턴을 만들 어주고 ${ }^{14,15}$ 깊은 호흡을 통해 배가로근, 배바깥빗근, 배속빗근, 골반바 닥근을 활성화하며, ${ }^{16}$ 허리와 골반주위 근육과 뼈 그리고 인대들의 협응력을 증진시킨다. ${ }^{17}$ 또한 복부 근육과 엉덩근육을 활성화하여 허 리골반의 안정성을 증가시켜, ${ }^{18}$ 척추의 중립성을 유도하여 월경 통증 을 감소시킨다.19

최근 월경 통증 관리법으로 골반의 안정성을 향상시켜 통증과 증 상을 경감시키는 필라테스를 적용한 연구 ${ }^{20}$ 가 주목을 받고 있지만 필 라테스와 유산소 운동군과 비교하여 월경통증, 허리장애지수, 월경 증상, 균형에 대한 항목을 연구한 연구는 아직 없으며 운동을 진행하 지 않은 대조군까지 비교하여 세 그룹의 결과를 본 연구는 많지 않고 어떤 운동군이 월경에 관련된 문제를 감소시킬 수 있을지 역시 알 수 없다. 따라서 본 연구의 목적은 다른 종류의 운동인 필라테스와 유산 소 운동을 비교하여 20 대 여자의 월경통증, 허리장애지수, 월경증상, 균형에 대해 어떤 운동이 더 유의한 효과가 있는지 확인하는 것이다.

\section{연구 방법}

\section{1. 연구 대상}

본 연구의 대상자는 대전광역시에 위치한 $D$ 대학교에 재학 중인 20 대 여성 중 월경 통증이 있는 자를 대상으로 실시하였다. 대상자는 월경 통증이 Visual analogue scale (VAS) 5점 이상인자, 월경통으로 진통제 복용이나 대체 요법을 실행하지 않는 자, 월경주기가 25-35일인 자, 월 경주기가 최소 3 개월 이상 규칙적인 자, 최근 3 개월 동안 일주일에 1 번 이상 규칙적으로 운동을 하지 않은 자로 선정기준을 삼았다. 또한 과 거 분만 경험이 있는 자, 자궁에 대한 부인과적 질환을 않고 있는 자 는 본 연구에서 제외하였다. 표본크기 설정을 위해 Yashika와 Vasanthi ${ }^{21}$ 의 선행연구를 참고하여 $\mathrm{G}^{*}$ power (version 3.1.9.4, Germany)을 이 용하여 유의수준 0.05 , 검정력 0.8 로 설정한 후 표본 크기를 산출한 결 과 각 표본의 집단은 11 명이었고, 탈락률 $20 \%$ 를 고려하여 총 39 명의 대상자수로 결정하였다. 모든 대상자는 연구의 목적과 과정에 충분 한 설명을 듣고 실험에 자발적으로 참여하였으며, 연구의 모든 절차 와 방법은 대전대학교의 기관생명윤리위원회의 심의를 받았다 (1040647-202104-HR-012-03).

\section{2. 측정도구 및 방법}

1) 통증(Visual analogue scale, VAS)

$100 \mathrm{~mm}$ 의 선에 한쪽 끝은 '통증 없음' 다른 한쪽 끝은 '참을 수 없는 최고의 통증으로 설명하고, 환자가 본인의 월경통의 수준 을 직접 표시하도록 하였다. ${ }^{22}$

\section{2) 허리장애지수(Korea Oswestry disability index, KODI)} 자기기입식 설문지로 허리장애지수 설문지로 통증수준, 개인위생, 물 건 들기, 보행, 앉아있기, 서 있기, 잠자기, 사회활동, 여행 및 이동 등의 10 개의 항목이 포함되어 있다. 점수 범위는 0 에서 5 점이며 환자의 평 가점수를 총점으로 나눈 뒤 백분율로 환산하여 표시한다. 점수가 클 수록 요통으로 인한 기능수행 정도가 낮은 것으로 판단할 수 있다.23

\section{3) 월경증상(Modified menstrual distress questionnaire, MDQ)} 월경증상은 Moos의 menstrual distress questionnaire의 월경증상도구 ${ }^{24}$ 를 Jung ${ }^{25}$ 이 수정·보완한 평가지로 통증(pain) 5 문항, 주의 집중(concentration) 3 문항, 행동변화(behavior change) 5 문항, 자율신경계 반응 (autonomic reaction) 9 문항, 수분 축적(water retention) 2 문항, 부정적 정 서(negative affect) 6 문항으로 6 개 영역으로 구성 되어있다. 점수 범위 는 1 에서 5 점이며 점수가 높을수록 월경증상이 심한 것을 의미한다. $\mathrm{MDQ}$ 는 Cronbach's $\alpha=0.91$ 로 높은 신뢰도를 가진다.

\section{4) 균형(Y balance test)}

균형평가는 Y balance test를 이용하여 전방(Anterior, A), 후방내측 (Posteromedial, PM), 후방외측(posterolateral, PL)의 3가지 방향으로 거 리를 측정한다. 한쪽 발로 지지한 상태에서 반대쪽 발을 이용해 세 방 향으로 최대한 멀리 다리를 뻗도록 유도하였으며, 방향에 대한 순서 는 무작위로 실시하였다. 맨발로 실시하였으며 양손은 골반 위에 위 치시켰다. 중심을 잃은 경우, 검사 실시 후 시작 자세로 돌아오지 못 하는 경우 그리고 발을 차는 경우 실패로 간주하고 재 측정하였다. 2 번 이상의 연습을 거친 후 한쪽 방향당 3 회씩 실시하였으며 도달 거 리를 측정하여 평균값을 기록하였다. 다리 길이에 따라 거리의 영향 이 있으므로 각 방향의 거리에서 다리길이를 나눈 후 백분율을 구해 상대 도달거리 측정값을 산출하였다. Y-균형 종합 점수(composite score)는 전방, 후방내측, 후방외측 길이를 다 더한 후 다리 길이의 3 배 값으로 나눈 후 백분율을 구한 점수도 산출하였다. ${ }^{26}$ 모든 대상자의 다리 길이는 바로 누운 자세에서 위앞엉덩뼈가시(anterior superior iliac crest)에서 안쪽 복사뼈(medial malleolus)까지의 거리를 측정하였 다. ${ }^{27} \mathrm{Y}$ balance test의 신뢰도는 측정자 간 신뢰도( $\left.\mathrm{r}=0.97-1.0\right)$, 측정자 내 신뢰도 $(r=0.85-0.89)$ 는 높게 나타났다.28 


\section{3. 실험절차}

본 연구는 중재 연구로 무작위 대조군 실험(randomized controlled trial)이며, 세 그룹 간 사전-사후 검사 설계(pretest-posttest design)이다. 대 상자 선정조건에 만족하는 대상자는 총 39 명으로 각 그룹당 13 명으 로 배정하였으나, 실험도중 필라테스 운동군의 나프록센 계열 소염 진통제 복용 $(\mathrm{n}=1)$, 유산소 운동군 운동거부 $(\mathrm{n}=2)$, 대조군의 이부프 로펜 계열 소염진통제 복용 $(\mathrm{n}=1)$ 의 이유로 탈락하여 최종적으로 필 라테스 운동군 12 명, 유산소 운동군 11 명, 대조군 12 명이 실험을 완료 하였다.

실험군에는 필라테스 그룹, 유산소 그룹이 있으며, 대조군은 중재 없이 실험을 진행하였다. 실험군은 4 주간, 주 3 회, 1 회 50 분으로 총 12 회 운동을 진행하였다. 사전-사후 평가는 연구대상자의 월경 이틀 째 에 균형평가를 실시하였으며, ${ }^{29}$ 통증, 허리장애지수, 월경증상에 대한 평가는 월경 마지막날 진행하였다. 중재는 첫번째 월경이 끝나는 날 을 시작으로 두번째 월경이 시작하는 날까지 시행하였다. ${ }^{13}$ 실험군에 는 기본적으로 운동자각도 척도를 기준으로 운동 강도를 정한다. 참 가자들은 최대 운동 강도의 $60-70 \%$ 로 운동하기에 운동자각도로 환 산한 점수를 사용한다. 6 (전혀 힘들지 않음)-20 (극도로 힘듦)의 척도 중 14 에서 16 사이의 숫자로 운동 강도를 맞추도록 하였다. ${ }^{30}$

필라테스 안정화 그룹을 지도하는 사람은 물리치료사이며 필라테 스 강사자격이 있는 자로 선정하였다. 필라테스 운동은 50 분 동안 진 행하였고 몸통의 안정성을 유지해야 하는 동작으로 구성하였다. 대 부분 허리 골반 안정화 운동으로 근력강화와 다른 관절과 협응성, 척

Table 1. Pilates exercise program

\begin{tabular}{|c|c|c|c|}
\hline & Exercise & Repeats & Week \\
\hline \multirow[t]{7}{*}{ Basic } & Roll up & 6 & $1-4$ \\
\hline & Hundred & 10-100 reps & \\
\hline & Single leg circles & 5 & \\
\hline & Rolling like a ball & 6 & \\
\hline & Single leg stretch & 5-10 reps & \\
\hline & Double leg stretch & 5-10 reps & \\
\hline & Spine stretch forward & 5 & \\
\hline \multirow[t]{12}{*}{ Intermediate } & Single straight leg & 10 & \\
\hline & Double straight leg & 10 & \\
\hline & Saw & 4 & \\
\hline & Single leg kicks & 5 & \\
\hline & Swimming & $15-25$ & \\
\hline & Side kick series & 5 each & \\
\hline & Criss cross & 10 & $2-4$ \\
\hline & Corkscrew & 5 & $3-4$ \\
\hline & Neck pull & 5 & \\
\hline & Double leg kick & $2-5$ & \\
\hline & Teaser & 3-5 reps & 4 \\
\hline & Seal & 6 & \\
\hline Advanced & Shoulder bridge & 3 & \\
\hline
\end{tabular}

추 유연성 등을 향상시킬 수 있는 20가지 동작으로 구성된 프로그램 을 실시하였으며 ${ }^{31}$ 주차별로 필라테스 프로그램 구성을 변경하였다 (Table 1).

유산소 그룹은 트레드밀(STEX 8020TL, STEX, Korea)을 이용하여 운동을 진행하였다. 필라테스 그룹과 마찬가지로 운동자각도를 기준 으로 운동강도를 설정하였으며 50분 동안 진행하였다. 주차 별로 운 동거리는 점점 늘려가도록 지시하였고, 대상자 간 운동거리의 차이가 있을 수 있음을 감안하였다.

중재가 없는 대조군은 월경 주기에 전-후 평가만 하도록 하였으며, 사후 평가가 종료된 후 원하는 운동군을 선택하게 하여 운동 프로그 램을 제공하였다.

\section{4. 자료분석}

본 연구를 통해 수집된 자료는 IBM SPSS $25.0 \mathrm{ver}$ 을 사용하여 통계처 리 하였다. 세 그룹 간의 나이, 키, 몸무게와 같은 일반적 특성은 기술 통계를 사용하여 평균과 표준편차를 제시하였고, 정규성 검정은 Shapiro-Wilk test를 실시하였다. 세 그룹의 그룹 내 전-후 효과 비교를 위해 paired t-test를 사용하였고, 그룹 간 비교를 위해 one-way ANOVA 를 사용하였다. 사후 분석은 Scheffe test를 이용하여 그룹 간 유의한 결과를 파악하였다. 본 연구의 통계학적 유의 수준은 $\alpha=0.05$ 로 설정 하였다.

\section{결 과}

\section{1. 대상자의 일반적 특성}

본 연구의 대상자는 총 35 명으로서 필라테스 그룹 12 명, 유산소 그룹 11 명, 대조군 12 명이 최종적으로 참여하였다. 대상자들의 나이, 키, 몸 무게와 같은 일반적인 특성에서 그룹 군 사이에 유의한 차이는 없었 다 $(\mathrm{p}>0.05)$. 본 연구에 참여한 대상자들의 일반적인 특성은 Table 2에 제시하였다.

\section{2. 대상자의 통증, 허리장애지수, 월경증상, 균형 변화}

1) 통증(VAS)

중재 전-후 VAS는 필라테스 그룹에서만 유의하게 감소하였고 $(\mathrm{p}<0.05)$,

Table 2. General characteristics of subjects

\begin{tabular}{lrrrr}
\hline & $\begin{array}{c}\text { Pilates group } \\
(n=12)\end{array}$ & $\begin{array}{c}\text { Aerobic group } \\
(n=11)\end{array}$ & $\begin{array}{c}\text { Control group } \\
(n=12)\end{array}$ & $F$ \\
\hline Age $(\mathrm{yr})$ & $22.1 \pm 0.3$ & $21.4 \pm 0.4$ & $22.7 \pm 0.6$ & 1.856 \\
Height $(\mathrm{cm})$ & $163.3 \pm 1.1$ & $160.3 \pm 1.4$ & $161.6 \pm 2.0$ & 0.942 \\
Weight $(\mathrm{kg})$ & $54.2 \pm 2.0$ & $55.6 \pm 2.5$ & $56.4 \pm 2.7$ & 0.230 \\
\hline
\end{tabular}

Mean \pm SD 
Table 3. Comparison of changes in three groups before and after exercise on VAS and ODI

\begin{tabular}{lcccc}
\hline & $\begin{array}{c}\text { Pilates group } \\
(\mathrm{n}=12)\end{array}$ & $\begin{array}{c}\text { Aerobic group } \\
(\mathrm{n}=11)\end{array}$ & $\begin{array}{c}\text { Control group } \\
(\mathrm{n}=12)\end{array}$ & $\mathrm{F}$ \\
\hline VAS $(\mathrm{cm})$ & & & & \\
pre & $6.33 \pm 0.35$ & $6.64 \pm 0.39$ & $6.50 \pm 0.31$ & 0.184 \\
post & $4.75 \pm 0.52^{*}$ & $5.55 \pm 0.55$ & $6.58 \pm 0.29$ & 4.061 \\
$\mathrm{t}$ & 5.506 & 1.671 & -0.561 & \\
change & $-1.58 \pm 0.29^{*}$ & $-1.09 \pm 0.65$ & $0.08 \pm 0.15$ & $4.621^{*}$ \\
ODI (score) & & & & \\
pre & $80.83 \pm 4.33$ & $89.09 \pm 2.13$ & $78.33 \pm 3.71$ & 2.399 \\
post & $88.50 \pm 3.08^{*}$ & $85.09 \pm 2.46$ & $74.50 \pm 4.68$ & 4.226 \\
t & -2.662 & 1.799 & 1.443 & \\
change & $7.68 \pm 2.88^{* *}$ & $-4.00 \pm 2.22$ & $-3.83 \pm 2.66$ & $6.583^{*}$ \\
\hline
\end{tabular}

Values are mean \pm SD

+Significant difference in aerobic group.

${ }^{4}$ Significant difference in control group.

${ }^{*} p<0.05$.

세 군 간 변화량 비교에서 사후 검정 결과 변화량은 필라테스 그룹을 유산소 그룹, 대조군을 비교하였을 때 유의한 감소가 나타났다 $(\mathrm{p}<0.05)$ (Table 3).

\section{2) 허리장애지수(ODI)}

중재 전-후로 ODI 점수는 필라테스 그룹에서만 유의하게 증가하였고 $(\mathrm{p}<0.05)$, 세 군 간 변화량 비교에서 사후 분석 결과 필라테스 그룹이 유산소 그룹과 대조군과 비교하여 유의하게 증가하였다 $(\mathrm{p}<0.05)(\mathrm{Ta}-$ ble 3).

\section{3) 월경증상(MDQ)}

중재 전-후 필라테스 그룹에서만 유의하게 $\mathrm{MDQ}$ 점수가 감소하였고 $(\mathrm{p}<0.05)$, 세 군 간 변화량 비교에서 사후 검정 결과 변화량은 필라테 스 그룹과 유산소 그룹, 대조군과 비교하였을 때 유의하게 감소한 것 으로 나타났다 $(\mathrm{p}<0.05)($ Table 4$)$.

\section{4) 균형(Y balance test)}

연구 대상자들의 중재 전-후 동적균형은 실험군에서 통계적으로 유의 하게 증가하였고 $(\mathrm{p}<0.05)$, 유산소 그룹은 Y balance test의 전방(A), 후방 외측(PL)과 종합점수(composite score)에서 유의한 증가가 있었다 $(\mathrm{p}<0.05)$. 세 군 간의 변화량 비교에서는 사후 분석 결과 군 간 유의한 차이가 있었는데, 전방(A) 방향은 필라테스와 유산소 그룹이 대조군 과 비교했을 때 유의하게 증가하였고 $(\mathrm{p}<0.05)$, 후방외측(PL) 방향은 필 라테스 그룹이 대조군과 비교했을 때 유의하게 증가하였다 $(\mathrm{p}<0.05)$. 후방내측(PM) 방향에서는 필라테스 그룹이 유산소 그룹, 대조군과 비 교했을 때 유의하게 증가하였으며 $(\mathrm{p}<0.05)$, 종합점수(composite score)
또한 필라테스 그룹이 유산소 그룹과 대조군과 배교하여 유의하게 증 가하였고 $(\mathrm{p}<0.05)$, 유산소 그룹도 대조군과 비교했을 때 유의하게 증 가하였다 $(\mathrm{p}<0.05)($ Table 5).

\section{고 찰}

본 연구는 일차성 생리통을 가진 20대 여성에서 필라테스 운동과 유 산소 운동을 중재로 적용했을 때 20대 여성에게 월경 통증, 허리장애 지수, 월경증상, 균형에 미치는 영향을 알아보았다.

본 연구의 결과에서 통증(VAS)의 결과는 필라테스 그룹만 전. 후, 군 간 유의한 감소가 있었다. 이는 필라테스가 월경 통증 부위인 복 부, 허리 부위를 안정화하는 운동이기 때문에 복부 근육을 활성화하 여 척추의 중립성을 유도함으로써 허리 골반의 수동적 안정성을 증 가시켜 월경 통증이 감소한 것으로 예상되며, 19,20 이는 필라테스 4 주 의 중재임에도 유의한 차이가 있었던 선행연구와 일치한다. ${ }^{32}$ 필라테 스는 일명 코어 근육을 강화하는 운동이며 일상생활에서도 코어 근 육을 사용할 수 있도록 운동을 진행하기 때문에 일상생활에서 근육 수축으로 인한 기계적자극이 통증 전달보다 민감하여 ${ }^{33}$ 통증에 유의 한 감소가 있는 것으로 생각된다. 유산소 그룹에서의 통증은 전. 후, 군 간 유의한 차이는 없었지만 통증이 줄어드는 것은 관찰할 수 있었 다. 유산소 운동은 하지의 교차적 운동으로서 하지근육의 근활성도 가 체간의 근활성도 보다 크기 때문에 ${ }^{34}$ 월경 통증이 나타나는 중심 부에서 영향은 적었을 것이라고 생각한다. 유산소 운동으로 4주 중 재 후 효과가 있었던 선행연구 ${ }^{13}$ 에서는 준비운동과 마무리운동에서 20 분간 골반의 스트레칭과 복부근육, 엉덩근육의 근력운동을 같이 진행하였기 때문에 유산소 운동만 진행한 본 연구와 차이점이 있었 다. 또한 8주 중재의 다른 선행연구에서 유산소 운동이 통증에 유의 한 감소가 있었다 ${ }^{35}$ 고 한 것을 바탕으로 생각해볼 때 월경통증을 유 의하게 감소시키려면 8주의 유산소 운동 중재가 필요하다고 생각된 다. 본 연구에서 유산소 운동은 유의한 효과가 없었지만 통증이 줄어 드는 양상을 관찰할수 있었던 것으로 보아추후 연구에서 월경통에 효 과적인 유산소 운동기간 대해 규명할 필요성이 있을 것으로 생각한다.

필라테스 운동 그룹을 유산소 그룹과 대조군에 비교해보았을 때 허리장애지수(ODI)에서 유의한 차이가 있었다. 허리 골반부 근육은 골반과 구조적으로 연결되어 있고 기능적으로도 상호 작용하기 때 문에 허리 골반부의 근육의 균형과 기능이 중요하다. ${ }^{36}$ 필라테스 운 동은 허리 골반부의 안정화가 기본적으로 바탕이 되는 운동이기 때 문에 본 연구에서 필라테스 운동이 더 허리장애지수(ODI)에 효과적 이었다고 생각된다. 필라테스와 유산소 운동을 비교한 선행 연구에 따르면 필라테스가 유의한 효과가 있었다고 하였고, ${ }^{37,38}$ 이는 본 연구 의 결과와 일치한다. 
Table 4. Comparison of changes in three groups before and after exercise on MDQ

\begin{tabular}{|c|c|c|c|c|}
\hline & Pilates group $(n=12)$ & Aerobic group $(n=11)$ & Control group $(n=12)$ & $\mathrm{F}$ \\
\hline \multicolumn{5}{|c|}{ MDQ total score } \\
\hline pre & $76.75 \pm 11.50$ & $74.46 \pm 16.90$ & $76.46 \pm 13.45$ & 0.089 \\
\hline post & $56.67 \pm 13.90$ & $72.82 \pm 19.34$ & $83.73 \pm 12.99$ & 8.778 \\
\hline $\mathrm{t}$ & $4.517^{\star}$ & 0.396 & $-3.669^{\star}$ & \\
\hline change & $-20.08 \pm 4.45^{+\neq}$ & $-1.64 \pm 4.14$ & $7.27 \pm 1.98$ & $14.200^{*}$ \\
\hline \multicolumn{5}{|l|}{ Pain } \\
\hline pre & $2.58 \pm 0.45$ & $2.84 \pm 0.84$ & $2.55 \pm 0.46$ & 0.756 \\
\hline post & $2.10 \pm 0.56$ & $2.93 \pm 1.02$ & $3.00 \pm 0.53$ & 5.454 \\
\hline $\mathrm{t}$ & $2.427^{\star}$ & -0.441 & $-2.930 \star$ & \\
\hline change & $-4.83 \pm 0.19^{+}$ & $0.91 \pm 0.21$ & $0.45 \pm 0.16$ & $6.379^{*}$ \\
\hline \multicolumn{5}{|c|}{ Concentration } \\
\hline pre & $2.44 \pm 0.46$ & $1.97 \pm 0.66$ & $2.03 \pm 0.64$ & 2.475 \\
\hline post & $1.92 \pm 0.62$ & $2.09 \pm 0.28$ & $2.70 \pm 0.55$ & 3.740 \\
\hline $\mathrm{t}$ & $3.171^{*}$ & -0.547 & $-3.597^{\star}$ & \\
\hline change & $-0.53 \pm 0.17^{\ddagger}$ & $0.12 \pm 0.22$ & $0.67 \pm 0.14$ & $9.947^{*}$ \\
\hline \multicolumn{5}{|c|}{ Behavior change } \\
\hline Pre & $2.77 \pm 0.76$ & $2.36 \pm 0.87$ & $2.71 \pm 0.80$ & 0.818 \\
\hline post & $2.00 \pm 0.64$ & $2.26 \pm 0.82$ & $2.76 \pm 0.77$ & 3.099 \\
\hline $\mathrm{t}$ & $3.700^{\star}$ & -0.711 & -1.000 & \\
\hline change & $-0.65 \pm 0.15^{+\neq}$ & $0.05 \pm 0.13$ & $0.23 \pm 0.11$ & $12.993^{*}$ \\
\hline \multicolumn{5}{|c|}{ Autonomic reaction } \\
\hline pre & $2.45 \pm 0.56$ & $2.17 \pm 0.49$ & $2.27 \pm 0.26$ & 1.118 \\
\hline post & $1.81 \pm 0.46$ & $2.22 \pm 0.20$ & $2.50 \pm 0.48$ & 4.991 \\
\hline $\mathrm{t}$ & $4.329^{\star}$ & -0.402 & -2.141 & \\
\hline change & $-0.65 \pm 0.15^{+\neq}$ & $0.05 \pm 0.13$ & $0.23 \pm 0.11$ & $12.993^{*}$ \\
\hline \multicolumn{5}{|c|}{ Water retention } \\
\hline pre & $2.92 \pm 0.87$ & $3.00 \pm 0.67$ & $3.27 \pm 1.03$ & 0.515 \\
\hline post & $2.25 \pm 0.89$ & $2.86 \pm 0.74$ & $3.50 \pm 1.07$ & 5.389 \\
\hline $\mathrm{t}$ & $4.000^{*}$ & 0.504 & -1.838 & \\
\hline change & $-0.67 \pm 0.17^{\ddagger}$ & $-0.14 \pm 0.27$ & $0.23 \pm 0.12$ & $5.398^{*}$ \\
\hline \multicolumn{5}{|c|}{ Negative affect } \\
\hline pre & $2.43 \pm 1.04$ & $2.83 \pm 0.94$ & $2.70 \pm 0.80$ & 0.555 \\
\hline post & $1.61 \pm 0.74$ & $2.48 \pm 0.63$ & $2.88 \pm 0.93$ & 8.176 \\
\hline $\mathrm{t}$ & $3.068^{*}$ & 1.456 & -1.117 & \\
\hline change & $-0.82 \pm 0.27^{+}$ & $-0.35 \pm 0.24$ & $0.18 \pm 0.16$ & $4.787^{\star}$ \\
\hline
\end{tabular}

Values are mean \pm SD.

MDQ: modified menstrual distress questionnaire.

+Significant difference in aerobic group.

*Significant difference in control group.

$* p<0.05$.

본 연구의 월경증상점수(MDQ)는 유산소 운동보다 필라테스 운 동군이 전·후, 군 간 유의한 차이가 있었으며 월경증상 $(\mathrm{MDQ})$ 중 행 동변화, 자율신경계 반응에 대한 항목에서 유산소 군과 유의한 차이 가 있었다. 행동변화에 대한 항목은 '결석이나 조퇴를 하는가', '수업에 지장이 있는가에 대한 질문 등이 있음을 생각해볼 때 유산소 그룹보 다 필라테스 그룹이 월경 중에도 일상생활이나 사회생활에 불편감 이 적었다는 것을 알 수 있다. 자율신경계 반응에 대한 항목은 메스 꺼움이나 식욕에 대한 질문이 있으며 유산소 운동보다 안정화 운동
인 필라테스가 월경기간 동안 일어나는 전반적인 신체 반응에 효과 적이라는 것을 알 수 있다. 현재 운동중재로 월경증상에 효과적인지 알아본 연구는 많았지만 월경증상(MDQ)의 세부적인 항목을 알아 본 연구는 많지 않으며 향후 연구에서 더 많은 연구가 이루어져야할 것 이다.

4 주 중재 후, 필라테스 그룹을 다른 그룹과 비교했을 때 동적균형 의 모든 항목(A, PM, PL)에서 유의한 차이가 있었으며 특히 후방내측 (PM)에서 필라테스 그룹이 유산소 그룹에 비해 유의하게 향상되었 
Table 5. Comparison of changes in three groups before and after exercise on $\mathrm{Y}$ balance test

\begin{tabular}{|c|c|c|c|c|}
\hline & Pilates group $(n=12)$ & Aerobic group $(n=11)$ & Control group $(n=12)$ & $\mathrm{F}$ \\
\hline \multicolumn{5}{|l|}{ Y-A (score) } \\
\hline pre & $64.01 \pm 1.63$ & $67.10 \pm 1.42$ & $66.00 \pm 2.09$ & 0.791 \\
\hline post & $75.16 \pm 3.01$ & $73.22 \pm 2.80$ & $62.09 \pm 1.26$ & 8.381 \\
\hline $\mathrm{t}$ & $-4.532^{*}$ & $-3.040^{\star}$ & $2.922^{*}$ & \\
\hline change & $11.42 \pm 2.58^{+}$ & $6.39 \pm 2.11^{*}$ & $-1.70 \pm 1.10$ & $11.019^{*}$ \\
\hline \multicolumn{5}{|c|}{ Y-PM (score) } \\
\hline pre & $62.49 \pm 1.93$ & $62.56 \pm 2.57$ & $63.14 \pm 3.09$ & 0.020 \\
\hline post & $70.11 \pm 2.23^{*}$ & $67.38 \pm 2.63$ & $63.23 \pm 3.18$ & 1.676 \\
\hline $\mathrm{t}$ & -6.886 & -2.808 & -0.067 & \\
\hline change & $7.35 \pm 0.68^{+, .}$ & $2.87 \pm 1.45$ & $0.98 \pm 0.80$ & $10.828^{*}$ \\
\hline \multicolumn{5}{|c|}{ Y-PL (score) } \\
\hline pre & $63.97 \pm 2.78$ & $68.87 \pm 2.79$ & $70.49 \pm 3.52$ & 1.254 \\
\hline post & $77.42 \pm 2.22^{*}$ & $75.44 \pm 2.59^{*}$ & $67.99 \pm 3.09$ & 3.580 \\
\hline $\mathrm{t}$ & -4.53 & -5.076 & 1.231 & \\
\hline change & $12.45 \pm 2.83^{+}$ & $4.92 \pm 1.11$ & $-0.40 \pm 2.03$ & $9.222^{*}$ \\
\hline \multicolumn{5}{|c|}{ Y-Composite } \\
\hline pre & $66.31 \pm 0.98$ & $69.85 \pm 1.18$ & $68.57 \pm 1.11$ & 2.691 \\
\hline post & $76.99 \pm 1.78^{*}$ & $74.75 \pm 1.62^{*}$ & $68.26 \pm 1.32$ & 8.687 \\
\hline $\mathrm{t}$ & -7.57 & -4.101 & 0.619 & \\
\hline change & $10.67 \pm 1.41^{+\neq}$ & $4.90 \pm 1.20^{\neq}$ & $-0.42 \pm 0.68$ & $24.606^{*}$ \\
\hline
\end{tabular}

Values are mean $\pm S D$.

Y-A: Y balance test anterior, Y-PL: Y balance test posterolateral, Y-PM: Y balance test posteromedial, Y-Composite: Y balance test Composite score.

Significant difference in aerobic group.

*Significant difference in control group.

${ }^{*} p<0.05$.

다. 후방내측(PM) 방향은 골반의 회전이 일어나기 때문에 골반의 안 정성과 하지의 근력이 중요하다. 후방내측(PM) 방향은 엉덩근육의 폄근, 벌림근 그리고 무릎 폄근이 사용되며, ${ }^{40}$ 이를 바탕으로 생각해 볼 때, 필라테스 그룹이 유산소 그룹에 비해 골반의 안정성을 만들어 주는 엉덩근육이 유의하게 향상되었다고 볼 수 있을 것이다.

필라테스 그룹의 후방내측 $(\mathrm{PM})$ 방향이 유산소 그룹과 비교하여 ${ }^{34}$ 유의하게 향상된 것은 엉덩근육이 활성화된다는 선행연구 ${ }^{39}$ 와 일치하 며 필라테스의 안정화운동이 하지의 교차 움직임을 사용하는 유산소 운동보다 엉덩근육을 활성화하는데 더 효과적이라고 볼 수 있다.

본 연구의 필라테스 프로그램은 4주의 단기간 중재임에도 여러 항 목에서 유산소 운동보다 유의미한 효과를 나타냈다. 이를 바탕으로 생각해보면 월경 평가의 모든 항목에서 유의미한 효과를 나타낸 만 큼 골반의 안정성과 코어 근육이 강화되었음을 알 수 있다. 본 연구는 다른 종류의 운동중재를 비교하였지만 추후 연구에서는 같은 종류 인 안정화 운동과 필라테스를 비교하여 월경에 관한 연구를 진행하 여야 할 것이다. 또한 본 연구의 필라테스 프로그램은 임상치료에 변 화를 줄 수 있을 것으로 예상되며 본 연구의 신뢰도를 높이기 위해 임 상 물리치료에 적용하여 다양한 분야에서 연구를 진행할 필요성이 있다고 생각된다.

\section{REFERENCES}

1. Kang DHS. Influencing factors in premenstrual syndrome (PMS) among nursing students. J Digit Converg. 2017;15(3):277-86.

2. Jin YK, Lee JH. A study on the efficacy of piroxicam in patients suffering from dysmenorrhea. Obstet Gynecol Sci. 1989;32(4):557-64.

3. Ju H, Jones M, Mishra G. The prevalence and risk factors of dysmenorrhea. Epidemiol Rev. 2014;36(1):104-13.

4. Deuster PA. Biological, social, and behavioral factors associated with premenstrual syndrome. Arch Fam Med. 1999;8(2):122.

5. Coco AS. Primary dysmenorrhea. Am Fam Physician. 1999;60(2):48996.

6. Mitchell DA, Esler DM. Pelvic instability - painful pelvic girdle in pregnancy. Aust Fam Physician. 2009;38(6):409-10.

7. Claeys K, Brumagne S, Dankaerts W et al. Decreased variability in postural control strategies in young people with non-specific low back pain is associated with altered proprioceptive reweighting. Eur J Appl Physiol. 2011;111(1):115-23.

8. Petrofsky J, Lee H. Greater reduction of balance as a result of increased plantar fascia elasticity at ovulation during the menstrual cycle. Tohoku J Exp Med. 2015;237(3):219-26.

9. Zahradnik HP, Hanjalic-Beck A, Groth K. Nonsteroidal anti-inflammatory drugs and hormonal contraceptives for pain relief from dysmenorrhea: a review. Contraception. 2010;81(3):185-96.

10. Armour M, Ee CC, Naidoo D, Ayati Z et al. Exercise for dysmenorrhoea. 
Cochrane Database Syst Rev. 2019;9(9):CD004142.

11. Motahari-Tabari N, Shirvani MA, Alipour A. Comparison of the effect of stretching exercises and mefenamic acid on the reduction of pain and menstruation characteristics in primary dysmenorrhea: a randomized clinical trial. Oman Med J. 2017;32(1):47-53.

12. Kannan P, Chapple CM, Miller D et al. Effectiveness of a treadmill-based aerobic exercise intervention on pain, daily functioning, and quality of life in women with primary dysmenorrhea: a randomized controlled trial. Contemp Clin Trials. 2019;81:80-6.

13. Byrnes $\mathrm{K}, \mathrm{Wu}$ PJ, Whillier S. Is Pilates an effective rehabilitation tool? a systematic review. J Bodyw Mov Ther. 2018;22(1):192-202.

14. Ji SH, Lee DG. Effects of lumbar stabilization exercise according to correct verbal instructions in pain and muscle strengthening of low back pain patient. Phys Ther Rehabil Sci. 2021;10(1):69-75.

15. Alves MC, de Souza Neto RJ, Barbosa RI et al. Effects of a Pilates protocol in individuals with non-specific low back pain compared with healthy individuals: clinical and electromyographic analysis. Clin Biomech (Bristol, Avon). 2020;72:172-8.

16. Kofotolis N, Kellis E, Vlachopoulos SP et al. Effects of pilates and trunk strengthening exercises on health-related quality of life in women with chronic low back pain. J Back Musculoskelet Rehabil. 2016;29(4):64959.

17. Torelli L, de Jarmy Di Bella ZI, Rodrigues CA et al. Effectiveness of adding voluntary pelvic floor muscle contraction to a pilates exercise program: an assessor-masked randomized controlled trial. Int Urogynecol J. 2016;27(11):1743-52.

18. Choi YG, Lee SY. Effects of pressure biofeedback application location for subjects with lumbar instability on pelvic rotation and hip joint abductor muscle activity during the clam exercise. Phys Ther Rehabil Sci. 2021; 10(2):90-7.

19. da Fonseca JMA, Radmann CS, de Carvalho FT et al. The influence of the Pilates method on muscular flexibility, symptoms, and quality of life in women with primary dysmenorrhea. Scientia Medica. 2016;26(2):6.

20. Kim MJ, Moon HJ. Effects of pilates stabilization exercise on abdominal muscles contraction, lumbopelvic alignment, dysmenorrhea. KSIM. 2020;8(2):75-88.

21. Yashika V, Vasanthi G. Effect of yoga and pilates on selected psychological variables on irregural menstrual cycle among college women. Int J Physiol Nutr Phys Educ. 2019;4(1):853-5.

22. Carlsson AM. Assessment of chronic pain. I. Aspects of the reliability and validity of the visual analogue scale. Pain. 1983;16(1):87-101.

23. Fairbank JC, Pynsent PB. The oswestry disability index. Spine (Phila Pa 1976). 2000;25(22):2940-52.

24. Moos RH. The development of a menstrual distress questionnaire. Psychosom Med. 1968;30(6):853-67.

25. Jung MK. Study on the menstrual knowledge, attitudes, symptoms and coping of the high school girls. Ewha woman's University. Dissertation of Master's Degree. 1999.

26. Shaffer SW, Teyhen DS, Lorenson CL et al. Y-balance test: a reliability study involving multiple raters. Mil Med. 2013;178(11):1264-70.

27. Son SM, Kang KW. Effect of action observation training using y-balance on balance capability in young adults. J Korean Phys Ther. 2020;32(2): 65-9.

28. Plisky PJ, Gorman PP, Butler RJ et al. The reliability of an instrumented device for measuring components of the star excursion balance test. $\mathrm{N}$ Am J Sports Phys Ther. 2009;4(2):92-9.

29. Şenol D, Uçar C, Toy Ş et al. Analysis of the effects of hypothalamic-pituitary-adrenal axis activity in menstrual cycle on ankle proprioception, dynamic balance scores and visual-auditory reaction times in healthy young women. J Musculoskelet Neuronal Interact. 2021;21(1):85-92.

30. Miyamoto GC, Franco KFM, van Dongen JM et al. Different doses of pilates-based exercise therapy for chronic low back pain: a randomised controlled trial with economic evaluation. Br J Sports Med. 2018;52(13): 859-68.

31. Rogers K, Gibson AL. Eight-week traditional mat pilates training-program effects on adult fitness characteristics. Res Q Exerc Sport. 2009; 80(3):569-74.

32. Jeong YW, Hong, SH, Lee SY. The effect of bridging exercise on dysmenorrhea back pain of women university students. KSIM. 2016;4(4):1-6.

33. Jeong HM, Shim JH, Suh HR. The passive stretching, massage, and muscle energy technique effects on range of motion, strength, and pressure pain threshold in musculoskeletal neck pain of young adults. Phys Ther Rehabil Sci. 2017;6(4):196-201.

34. Jang JS, Park KD. Comparison of muscle activity during walking on non-motorized treadmill, motorized treadmill and overground. Korean J of Sport Sci. 2019;28(4):1287-96.

35. Dehnavi ZM, Jafarnejad F, Kamali Z. The Effect of aerobic exercise on primary dysmenorrhea: a clinical trial study. J Educ Health Promot. 2018;7:3.

36. Lin HT, Hung WC, Hung JL et al. Effects of pilates on patients with chronic non-specific low back pain: a systematic review. J Phys Ther Sci. 2016;28(10):2961-9.

37. de Oliveira NTB, Ricci NA, Dos Santos Franco YR et al. Effectiveness of the Pilates method versus aerobic exercises in the treatment of older adults with chronic low back pain: a randomized controlled trial protocol. BMC Musculoskelet Disord. 2019;20(1):250.

38. Shakeri H, Fathollahi Z, Karimi N et al. Effect of functional lumbar stabilization exercises on pain, disability, and kinesiophobia in women with menstrual low back pain: a preliminary trial. J Chiropr Med. 2013;12(3): 160-7.

39. Lee DK, Kim GM, Ha SM et al. Correlation of the Y-balance test with lower-limb strength of adult women. J Phys Ther Sci. 2014;26(5):641-3. 